\title{
Experimental and Optimization Study on the Sliding Force Monitoring and Early Warning System for High and Steep Slopes
}

\author{
Ligang Wang $\mathbb{D},{ }^{1,2,3}$ ZhiGang Tao $\mathbb{D}^{1,2}$ ManChao He, ${ }^{1}$ and Xiaocong Yang $\mathbb{D}^{3}$ \\ ${ }^{1}$ State Key Laboratory for GeoMechanics and Deep Underground Engineering, Beijing 100083, China \\ ${ }^{2}$ School of Mechanics and Civil Engineering, China University of Mining and Technology (Beijing), Beijing 100083, China \\ ${ }^{3}$ Beijing General Research Institute of Mining \& Metallurgy, Beijing 102628, China \\ Correspondence should be addressed to Xiaocong Yang; yxcong@bgrimm.com
}

Received 16 September 2019; Revised 21 December 2019; Accepted 28 January 2020; Published 16 April 2020

Academic Editor: Zaobao Liu

Copyright (c) 2020 Ligang Wang et al. This is an open access article distributed under the Creative Commons Attribution License, which permits unrestricted use, distribution, and reproduction in any medium, provided the original work is properly cited.

\begin{abstract}
A series of high and steep slopes have been formed due to the deep exploitation of resources in open-pit mines across China. The stability of these high and steep slopes has become an essential factor affecting the efficient, safe, and sustainable development of deep mineral resources. Due to numerous problems such as constant resistance fluctuation and pipe jamming of the original sliding force monitoring system, leading to system failure, a series of improvements on the current monitoring systems were implemented. This specific work included a mechanical characteristics test of the anchor cable, improvement of the constant resistance structure, and measurement of the internal displacement of the slope. The communication mode and the software architecture of the system were also adjusted. This work significantly improved the overall performance of the sliding force monitoring and early warning system. The improvements performed in this research are systematically described to provide an example of good practice for other sites with similar features. The collected data show that the improved sliding force monitoring system can accurately reflect the whole process of landslide incubation. Moreover, the validity of the early warning criterion based on the sliding force is verified again using the field test.
\end{abstract}

\section{Introduction}

With the exhaustion of shallow surface resources in open-pit mines, the mining depth and slope height are continually increasing and a series of high and steep slopes have been formed along the peripheries of the mines. Due to rainfall, weathering, and blasting within the mine, the rock strength deteriorates with time [1-6], affecting the slope stability of an open-pit mine. The stability of these slopes has become an essential factor affecting the efficient, safe, and sustainable development of deep mineral resources. Continuous monitoring is required to ensure the stability of these high-steep slopes and transmission of early warnings of landslides.

Early landslide monitoring largely infers the possibility of landslide occurrence through changes in surface fissures and groundwater levels. For example, Pirone et al. [7] evaluated the stability of an unsaturated volcanic ash slope through in situ groundwater monitoring data. With the progress of technology and the improvement of equipment conditions, a series of monitoring technologies, such as surface displacement and internal displacement monitoring, have gradually been applied in the field. The leading technical equipment includes GPS, In-SAR, GB-SAR, threedimensional laser scanning, and in-place inclinometer. Salvoni and Dight [8] used internal deformation monitoring and microseismic monitoring technology to study the deep rock damage mechanisms and slope stability of an open-pit slope in Queensland, Australia. Ohnishi et al. [9] used digital photogrammetry to analyze the evolution of slope stability behavior. Osasan and Stacey [10] used the inverse velocity method to analyze slope monitoring data of an MSR landbased real-aperture radar and verified the effectiveness of the SFPM model in advance warning in the case of slope excavation. Xu et al. [11] applied three-dimensional laser scanning technology to open-pit slope monitoring. Through DEM comparison of scanning data in different periods and 
combined with field survey results, the feasibility of threedimensional laser scanning technology applied to mine slope monitoring was confirmed. Jun et al. [12] used low-altitude UAV to carry a digital camera to acquire an image sequence of a slope, quickly construct the fine terrain of an open-pit slope, and monitor the dynamic deformation of the open-pit slope with potential hazards. Guobin et al. [13] used an SSR slope radar to continuously monitor a mine slope's various weather patterns and used a slope radar scanning image to classify the risk grade of the mine slope. The stability of the mine slope was determined by the change in the curve of the displacement value compared to the displacement rate. Chen et al. [14] studied the application of time-domain reflectance (TDR) on landslide monitoring, testing the theory using indoor simulations and field applications. Tao et al. [15] installed a sliding inclinometer on the side slope of an openpit coal mine in Xinjiang, China. Only by monitoring the data, the position of the potential slip weak surface was determined, which provided guidance for engineering treatment. Dandan et al. [16] built a monitoring and early warning system for high and steep slopes in the Daye Openpit Iron Mine based on GPS and GIS technology. The GPS and GIS data were correlated, and potential slope landslides were comprehensively analyzed to issue early warnings to the mine. Lei et al. [17] used time-series In-SAR technology to obtain the deformation range, deformation rate, and timeseries deformation values of the Daguangbao landslide experimental area and evaluated the stability of the landslide area after the Wenchuan earthquake. These previous studies provide valuable methods for landslide disaster monitoring and early warning systems. Criteria for landslide occurrence and slope stability have previously been established using these various monitoring methods, which provide adequate reference for monitoring of other sites.

However, numerous studies and practices show that monitoring indicators such as surface deformation and groundwater osmotic pressure are just the necessary conditions for landslides to occur. The basic principle of mechanics shows that the Newtonian force is the basis of displacement. The sliding force on the potential sliding surface of a slope is the sufficient and necessary factor for the occurrence of a landslide. However, because the sliding force of a slope belongs to the natural mechanical system, it cannot be measured directly.

In view of the above problems, He $[18,19]$ suggested that the sliding force can be calculated by an artificial mechanical system. The process of slope instability changes from quantitative to qualitative, from gradual change to final failure of the slope. The time and precise location of a landslide can be accurately predicted by real-time monitoring of variations in the deep sliding force acting on the slope rock mass. A mechanical model used in sliding force monitoring can then be created based on the above findings. Therefore, a system of remote sensing monitoring and early warning for landslides based on the sliding force variation can be developed, which achieves the monitoring and early warning of deep sliding force for the first time [19]. However, in the process of engineering application, the system encounters a series of engineering adaptability problems, such as unstable constant resistance and constant resistance body jamming, resulting in system failure and discontinued monitoring.

In this paper, the authors improved the component structure and the installation mode of the monitoring system proposed by He [19] and upgraded the communication method and the upper computer software architecture to significantly improve the applicability and validity of the system. An engineering monitoring case is also used to illustrate the effectiveness of the above work.

\section{System Improvement}

The original system was proposed by He [19] in 2009 and applied in a series of engineering monitoring sites. The original system adds a constant resistance section and a mechanical measuring device to the ordinary slope reinforcement anchor cable to measure the sliding force. Wired or wireless communication sends the data to be stored in a physical server. The expansibility of the system is limited, and the reliability of data transmission is not adequate due to the typically complex environment of the project site.

\subsection{Improvement of Mechanical Conduction System}

2.1.1. Mechanics Characteristic Test of Anchor Cable Bundle. A constant resistance and large deformation anchor cable is a component of energy absorption and aids in resistance to large deformation by adding a constant resistance device to the conventional anchor cable. Firstly, the pullout test was performed to determine the mechanical properties of the anchor cable bundle to achieve economic, reasonable, and practical mechanical matching between the anchor cable bundle and the constant resistance device. According to the mechanical characteristics of several anchor cable bundles, the static tension tests (Table 1) were performed to determine the optimal number of anchor cable bundles with fixed anchor cable materials (1*7-15.24-1860 steel strands, $15.24 \mathrm{~mm}$ ) and length components (length is $4 \mathrm{~m}$, determined by the maximum size of the anchor cable allowed by the tensile test system).

Based on the nominal mechanical properties of a single $15.24 \mathrm{~mm}$ anchor cable, the stress-strain characteristics of the anchor cable bundles with different combination modes were determined and the variations in yield strength and elastic modulus with varying numbers of anchor cables were obtained. This also provided the quantitative effects of the mechanical properties of the anchor cable bundles. Using the static tension test on the steel strand, the recorded data were summarized, and the stress-strain curves of each group of test anchor cables are shown in Figure 1.

The elastic modulus $E$ of the steel strand was calculated by taking two data points $\left(0.2-0.6 \sigma_{\text {pek }}, \sigma_{\text {pek }}\right.$ is yield stress $)$ as far as possible in the straight section within a stable slope (Table 2). At the same time, the nominal elastic modulus of a single strand was included as one of the underlying data for numerical fitting analysis.

The quantitative effects of anchor cable bundles under different strand numbers were analyzed, and the empirical 
TABLE 1: Quantitative effect test scheme for mechanical properties of anchor cable bundles.

\begin{tabular}{lccc}
\hline Group number & Test materials & Length $(\mathrm{m})$ & Number of anchor cables \\
\hline 1 & & 4 & 2 \\
2 & $1 * 7-15.24-1860$ steel strand & 4 & 3 \\
3 & & 4 & 4 \\
4 & & 4 & 5 \\
5 & 4 & 6 \\
\hline
\end{tabular}

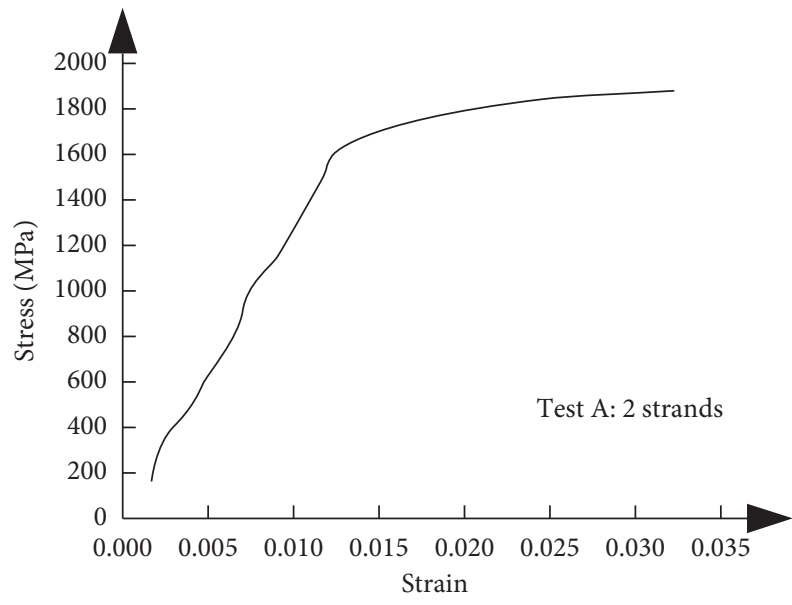

(a)

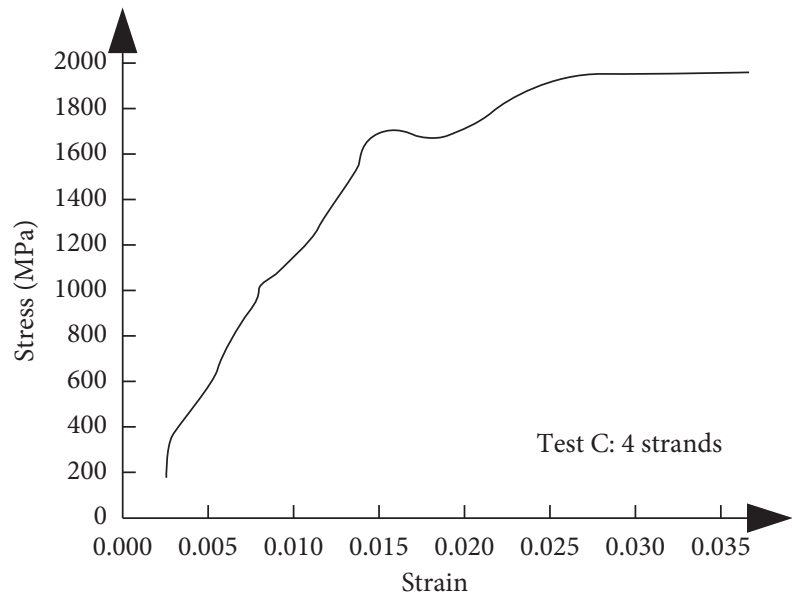

(c)

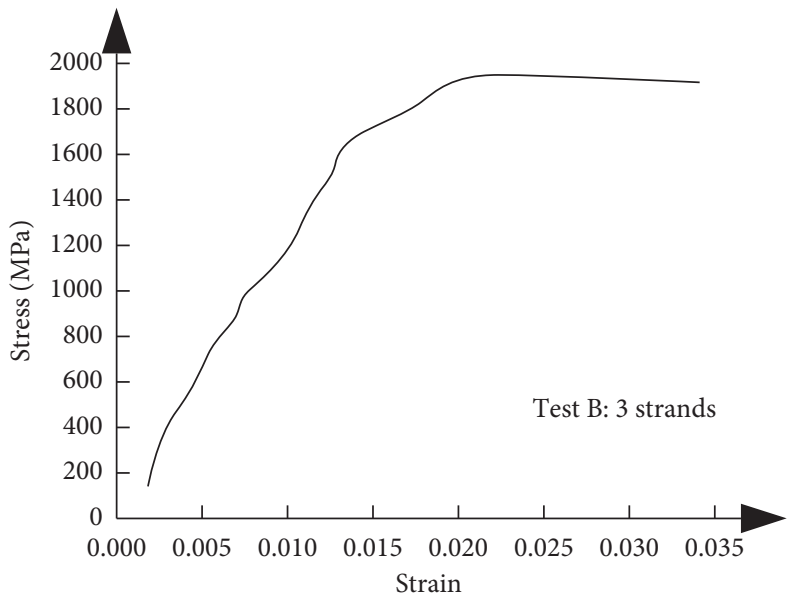

(b)

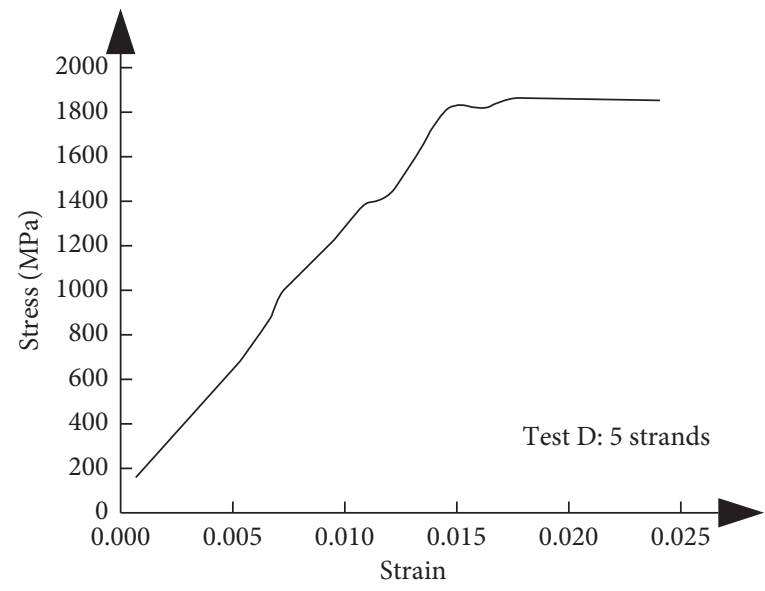

(d)

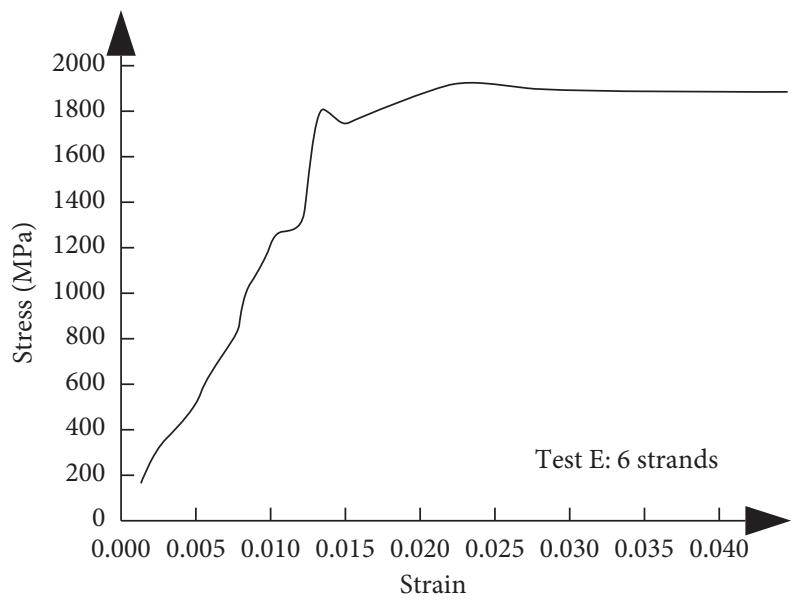

(e)

Figure 1: Static tensile test results with varying strand numbers. (a) Static tensile test results of 2 strands, (b) static tensile test results of 3 strands, (c) static tensile test results of 4 strands, (d) static tensile test results of 5 strands, and (e) static tensile test results of 6 strands. 
TABLE 2: Test results of elastic modulus of the multistrand steel wire.

\begin{tabular}{lccccc}
\hline Quantity of strands & Yield stress $(\mathrm{MPa})$ & Tensile strength $(\mathrm{MPa})$ & Yield force $(\mathrm{kN})$ & Peak tension $(\mathrm{kN})$ & Elastic modulus $(\mathrm{GPa})$ \\
\hline 1 & 1600 & 1860 & 290 & 340 & 198 \\
2 & 1603.506 & 1860.842 & 585.006 & 678.890 & 190.146 \\
3 & 1604.580 & 1868.393 & 878.097 & 1022.467 & 188.722 \\
4 & 1604.046 & 1864.386 & 1170.407 & 1360.365 & 186.306 \\
5 & 1607.184 & 1867.875 & 1465.870 & 1703.639 & 185.977 \\
6 & 1602.819 & 1861.140 & 1754.266 & 2036.996 & 185.407 \\
\hline
\end{tabular}

curves of elastic modulus En of anchor cable bundles varying with the number of strands were fitted, as shown in Figure 2.

As can be seen from Figure 2, the equivalent elastic modulus decreases with the increase in the number of strands. The empirical formula for the decrease of the equivalent elastic modulus of strands from 1 to 6 was fitted by the least square method:

$$
E_{n}=185.494+28.723 e^{-0.942 n}, \quad 1 \leq n \leq 6,
$$

where $n$ represents the number of strands and $E_{n}$ represents the equivalent elastic modulus of the multistrand steel wire $(\mathrm{GPa})$

The empirical curves of the peak tension and yield force with varying numbers of strands were analyzed, as shown in Figure 3.

Overall, with the increase in strand number, the yield force and peak tension of anchor tendons increase linearly. The empirical formula of the fitting relationship between tension and strand number by the least squares method is as follows:

$$
\begin{aligned}
F_{t} & =339.92 n+0.6803, \\
F_{\text {pek }} & =293.04 n-1.6822, \\
1 & \leq n \leq 6,
\end{aligned}
$$

where $F_{t}$ is the peak tension of the anchor cable bundle, $\mathrm{kN}$, and $F_{\text {pek }}$ is the yield force of the anchor cable bundle, $\mathrm{kN}$.

2.1.2. Component Structure Improvement. The constant resistance and large deformation anchor cable is connected to the conventional anchor cable bundle by six groups of 12$\mathrm{mm}$ wedge-type anchorage. The clamps are not loosened by the compression of the cushion plate and the axial tension of the strand. The constant resistance body (blue part in Figure 4) is a steel cylinder with a smooth surface and unequal top and bottom. Six axially symmetrical throughholes are distributed around the axis of the cylindrical cylinder, which is used to penetrate through and cause tension on the steel strand. The constant resistance value was designed according to $90 \%-92 \%$ of the yield strength of the anchor strand. When the load along the axis of the steel strand reaches the constant resistance value, the constant resistance body will slip along the wall of the constant resistance casing pipe. The anchor cable bundle is not destroyed, rather the pipe wall of the constant resistance casing undergoes elastic-plastic deformation under viscoelastic stress and produces intense heat. This process absorbs the deformation energy generated by the landslide.
Therefore, the anchor cable after adding the constant resistance device is able to absorb the constant resistance energy and resist large deformation. The schematic diagram of the constant resistance device is shown in Figure 4 [20].

When the axial load applied on the steel strand is less than or equal to the constant resistance value, the external load is mainly resisted by the elastic deformation of the anchor cable bundle. When the axial load applied on the steel strand is higher than the constant resistance value, the cylinder in the constant resistance casing begins to slide along the inner wall of the constant resistance casing and the structural deformation of the constant resistance sleeve resists the external load. The structure design ensures that the cable does not break with up to $2 \mathrm{~m}$ of deformation [21].

Yet, in practice, it is found that the difference between the diameters of the two circular planes determines whether the constant resistance body can slide smoothly and produce a constant antislide force in the casing. If the diameter difference is small, it is unable to reach the preset constant resistance value. Inversely, if the diameter difference is significant, the constant resistance body will produce considerable friction in the casing, potentially producing uneven skin scratches on the inner wall of the constant resistance casing (Figure 5). These scratches are reflected in the sliding force monitoring curve as irregular wave-like jumps in the constant resistance characteristic curve. Furthermore, because of the tearing of steel in the inner wall of the casing, the front end of the constant resistance body will be extruded and staggered, which will cause the constant resistance body to become stuck and unable to slip. In this condition, the constant resistance characteristic curve will rise straight up and exceed the preset constant resistance value until the strand is broken and the system will fail.

In order to solve the above problems, the mechanical model of the constant resistance body was studied. The constant resistance casing with an inner diameter of $93 \mathrm{~mm}$ and an outer diameter of $133 \mathrm{~mm}$ is adopted. Based on the combined scheme of the end face diameter of the constant resistance body, a chip groove was designed on the cylindrical surface of the constant resistance body to remove the scraps generated during the sliding process of the constant resistance body and prevent scrap accumulation and extrusion from forming a staggered platform. A screw thread was made on the cylindrical surface of the constant resistance body. This thread causes the friction between the constant resistance body and the constant resistance casing to be linear, alleviates the constant resistance fluctuation caused by the setback slip, and optimizes the constant resistance characteristics (Figure 6). 


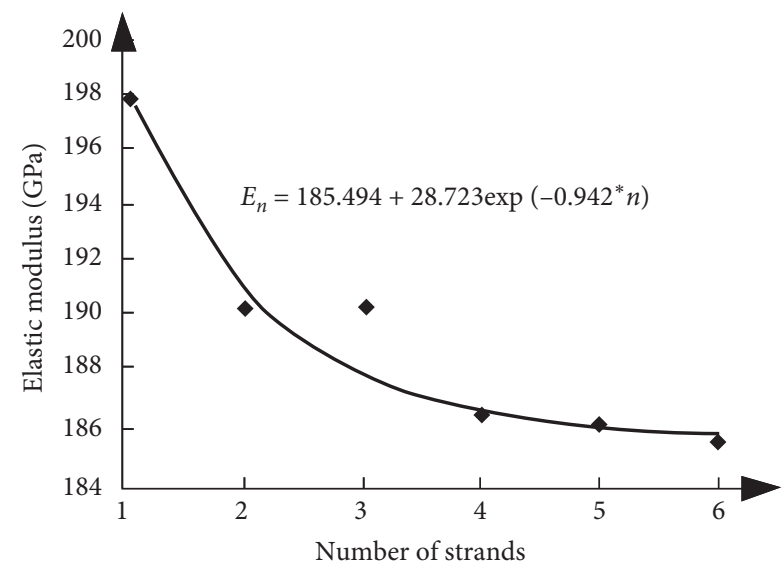

FIgURE 2: Empirical curve of elastic modulus-strand number relationship.

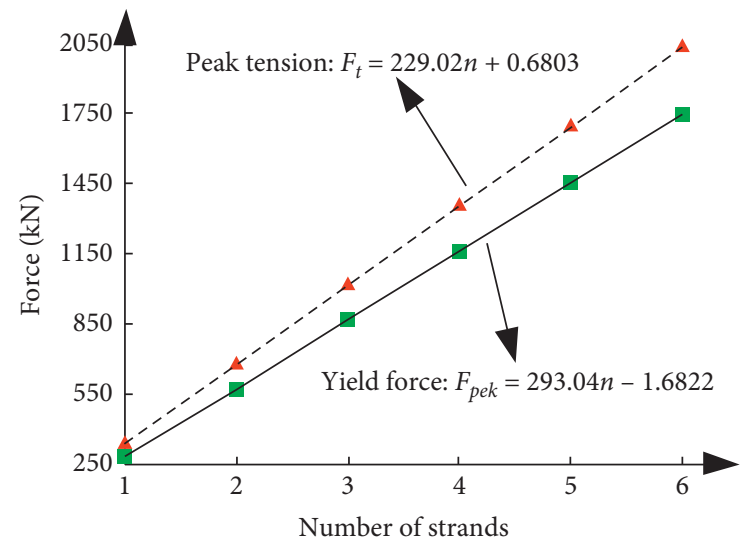

Figure 3: Experience curve of tension-strand quantity relationship.

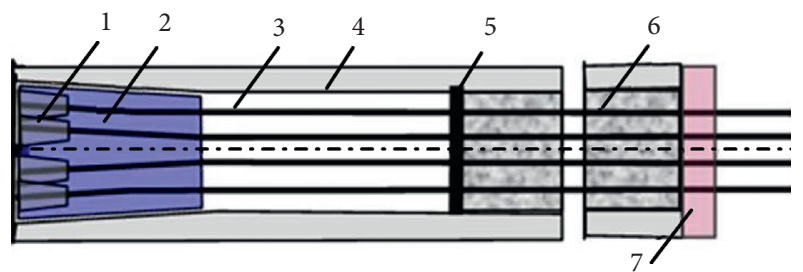

FIGURE 4: Schematic diagram of the constant resistance device [16] (1, steel strand group anchor clip; 2, constant resistance body; 3 , steel strand; 4, constant resistance casing; 5, antiwinding slurry barrier; 6 , filling material; 7 , antiskid baffle).

Experiments were designed to test the static tension of the constant resistance device (Table 3 and Figure 7). The constant resistance body was made of No.45 steel with dimensions of $(\mathrm{D} * \mathrm{~A} * \mathrm{~L}) 93.9 * 92.5 * 150 \mathrm{~mm}$. The constant resistance casing was made of No.20 steel with an outer diameter of $133 \mathrm{~mm}$, an inner diameter of $93 \mathrm{~mm}$, a whistle length of $150 \mathrm{~mm}$, a whistle outer diameter of $113 \mathrm{~mm}$, and an inner diameter of $93 \mathrm{~mm}$. The device was tested under four conditions: no thread and chip guide groove; only thread; only chip guide groove; and adding thread and chip guide groove. The static tension test of the whole set of the

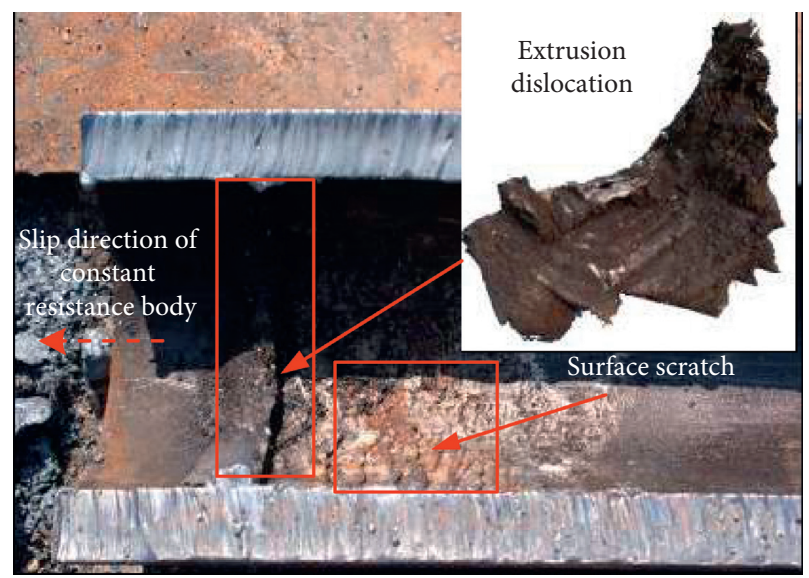

FIGURE 5: Surface scratch and dislocation produced by sliding extrusion of the constant resistance body.
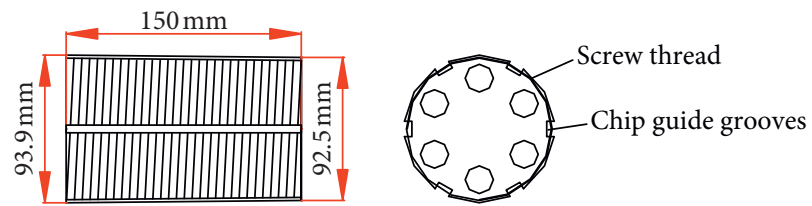

FIgURE 6: Structure optimization scheme of the constant resistance body.

TABle 3: Structural optimization experiment scheme of the constant resistance body.

\begin{tabular}{lcc}
\hline Test no. & Screw thread & Chip guide grooves \\
\hline A & No & No \\
B & No & Yes \\
C & Yes & No \\
D & Yes & Yes \\
\hline
\end{tabular}

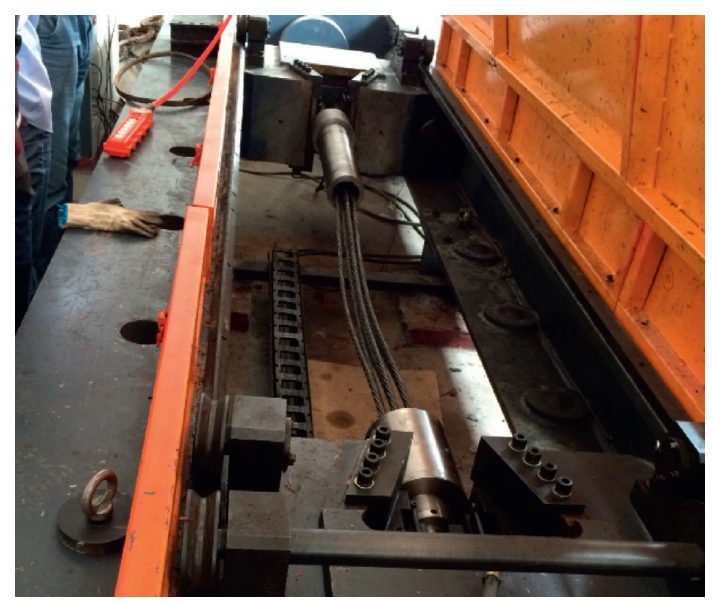

Figure 7: Static tensile experiment.

constant resistance device was performed on an HWL-2000 static tension test system. The constant resistance curve under static loading was observed to verify the optimization effect of adding the thread and chip guide groove. 
The test results show that the sliding force monitoring curve fluctuates sharply without threads and chip guide grooves (Figure 8(a)). The sliding force monitoring curve fluctuates only slightly when only threads or chip guide grooves were added to the instrument (Figures 8 (b) and $8(\mathrm{c})$ ). After adding both threads and chip guide grooves (Figure $8(\mathrm{~d})$ ), the sliding force monitoring curve was smooth with constant resistance. The experimental results show that the curve of the constant resistance can be optimized by synthetically adding threads and chip guide grooves, and the problems of constant resistance clamping and constant resistance fluctuation can be prevented.

2.1.3. Installation Improvement. In the initial stage of industrial application of a large deformation cable with constant resistance, the constant resistance device is usually installed at the bottom of the hole and grouted and anchored to the bedrock. The force sensor and anchor ring are added to the steel strand at the borehole entrance, and a prestressing force is applied along the axial direction of the steel strand to form a sliding force measurement system (Figure 9). Through engineering practice, it is found that there are at least the following problems in this installation method:

(1) Due to the inevitably deviated holes in the drilling process conducted by construction machinery, it is easy to jam the constant resistance device and challenging to reach the bottom of the hole smoothly. Moreover, the surface of the constant resistance device is abraded during the installation process. The corrosion resistance of the internal components of the constant resistance device is lessened after grouting, which reduces the service life of the constant resistance and the large deformation cable.

(2) The constant resistance device is located at the bottom of the hole and is far from the borehole entrance. The slip distance of the constant resistance body in the constant resistance casing (approximately equal to the displacement of the landslide body) cannot be measured.

(3) The anchoring agent around the constant resistance casing exerts lateral restraint on the constant resistance device, which affects the structural deformation mechanism of the constant resistance casing and makes the predesigned constant resistance difficult to control.

In order to solve the above problems, the reversed installation of the large deformation cable with constant resistance was studied. Because the steel strand has radial flexibility characteristics different from the rigid structure of the constant resistance device, it is easy to place the steel strand with the anchorage head and grouting anchorage at the bottom of the hole. The constant resistance device is placed at the borehole entrance, and the prestressing force on the steel strand at the end of the orifice will anchor the sensor and the anchor ring in the axial direction of the steel strand (resistance to landslide). This installation method avoids the above problems, reduces the construction cost, and is easier to maintain.

At the same time, a set of displacement sensors is installed on the pipe wall at the end of the constant resistance casing. The cable end of the displacement sensor is connected to the constant resistance body, which is used to measure the displacement of the constant resistance body in the constant resistance casing (Figure 10). Because the constant resistance device is installed in the orifice, the sensor signal line can easily lead to the acquisition system and accurately measure the sliding distance of the constant resistance body in the constant resistance casing. The internal displacement of the landslide body is actually measured indirectly, which solves the issue of the system not obtaining internal displacement and deformation of the slope in the process of landslide incubation.

2.2. Improvement of Communication System. It is inconvenient and difficult to maintain wired communication lines when a safety monitoring system is built on a high and steep slope. To overcome this, at the beginning of the construction of the sliding force monitoring and early warning system, the GPRS wireless data transmission method was implemented. A set of GPRS wireless data transmitting and receiving devices was installed on the remote server side, and a set of GPRS wireless data transmitting and receiving devices was installed at every sliding force monitoring point on the slope site. Data exchange only occurred with the server at each monitoring point on the site, which was a typical star network. Each monitoring point on the server side and the site needed a separate receiving and sending device to support data flow for wireless data transmission and reception. Generally, if the number of monitoring points is large, more GPRS transceiver devices are needed, and the construction cost and later operation costs are high and difficult to manage.

In addition, mines are generally located in remote mountainous areas, and there may be blind areas or signal drift in the network coverage of mobile operators, which causes uncertainty in the remote data acquisition relying on GPRS transmission. To solve these issues, a framework for the transmission network is improved. "Regional data aggregation + remote dual redundant transmission" allows for highly reliable data transmission. First, a low-power wide-area network (LPWAN) allows for a wireless transmission convergence system that can cover the installation area of the monitoring points on the slope. LoRa (Long Range Radio), an ultralong-distance wireless transmission scheme based on spread spectrum technology, was adopted to implement the system, which significantly expands the coverage of the wireless sensor networks (Figure 11).

In the application of the sliding force monitoring system, only the LoRa data transmission module was installed at each sliding force monitoring point, and the LoRa gateway was set at the center of the area in the coverage area. The data from the sliding force monitoring points distributed in the mine slope area are gathered, and then the remote data 


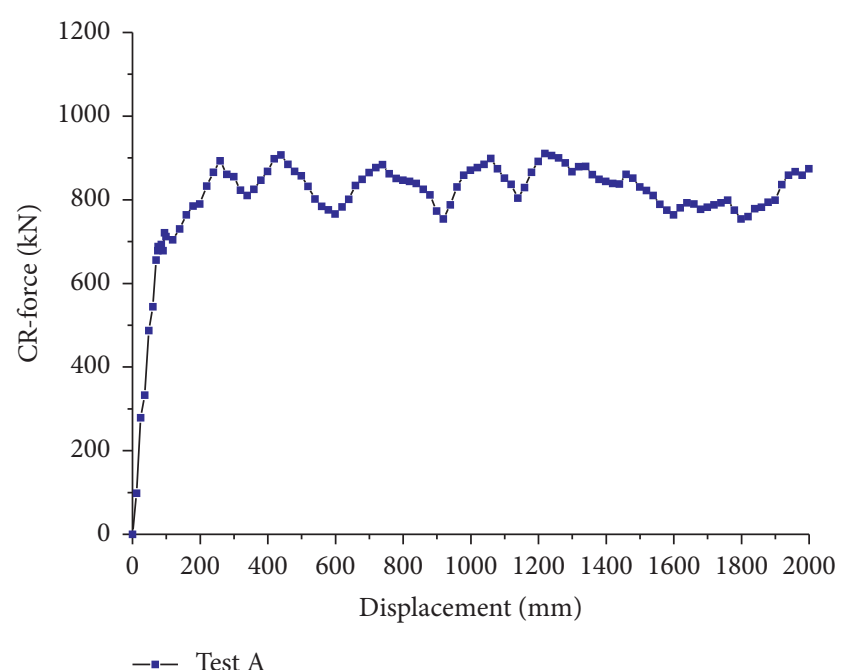

(a)

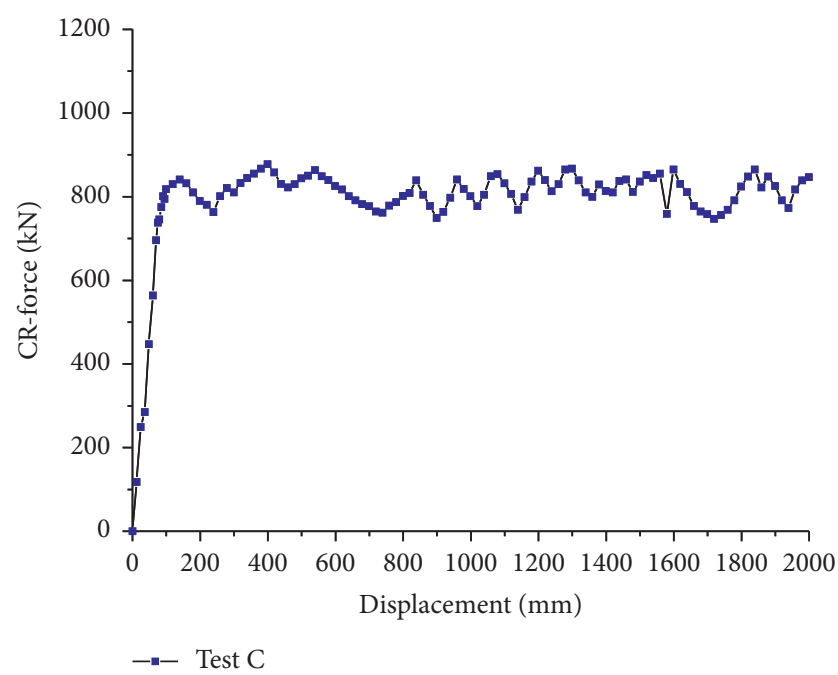

(c)

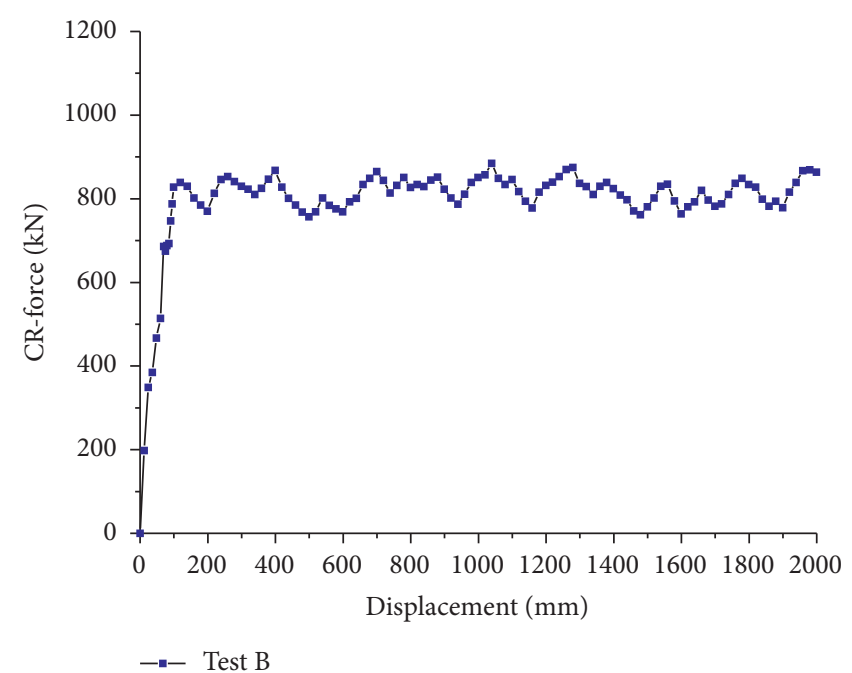

(b)

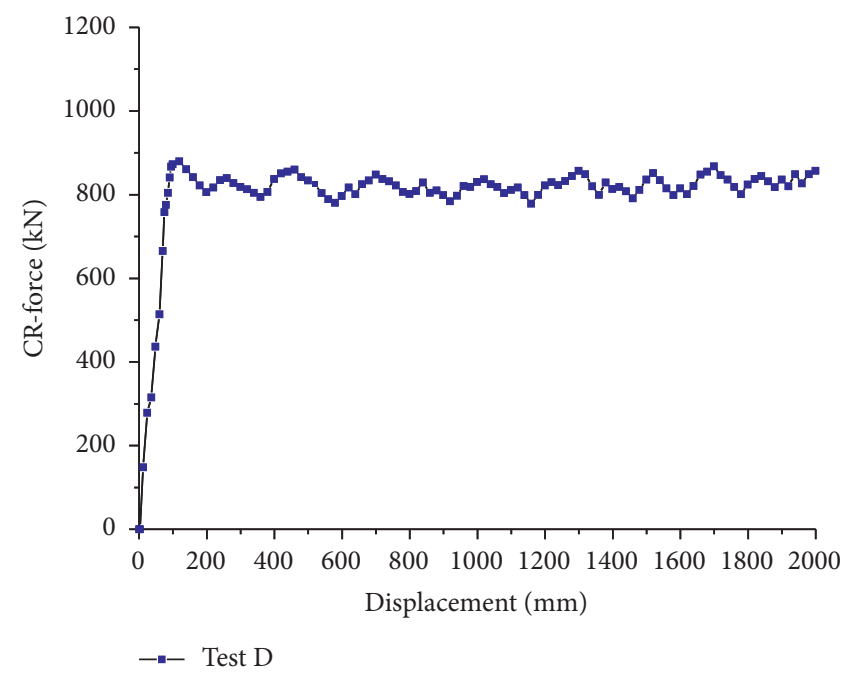

(d)

FIGURE 8: Constant resistance characteristic curve under different constant resistance structures.

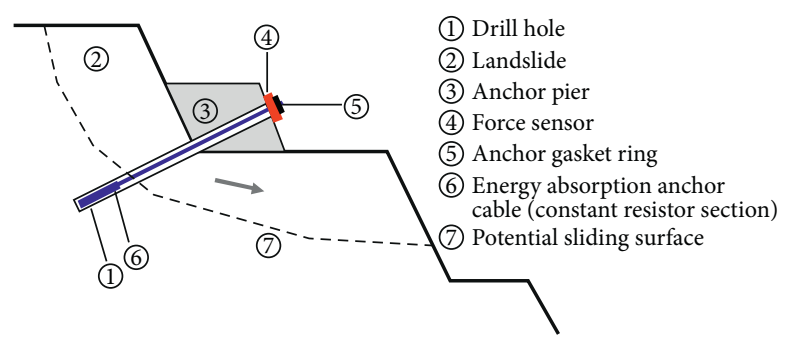

FIgURE 9: Conventional installation method of the NPR cable.

transmission is carried out through the LoRa gateway to the mobile operator network (GPRS/3G/4G), which forms a star-type local area monitoring connected to the wide-area network and allowing for remote data acquisition. At the same time, in order to ensure the reliability of remote data communication, redundant communication was adopted from the data gathering point to the remote server to improve reliability. A Beidou satellite communication system was used as a parallel backup of the mobile operator GPRS/3G/4G network. Two sets of data are sent at the same time. The upper computer software on the server side sets up the data receiving mechanism, and two sets of data are stored in the database, one after another. In the two tables, the upper computer software will call the data in the table in turn 

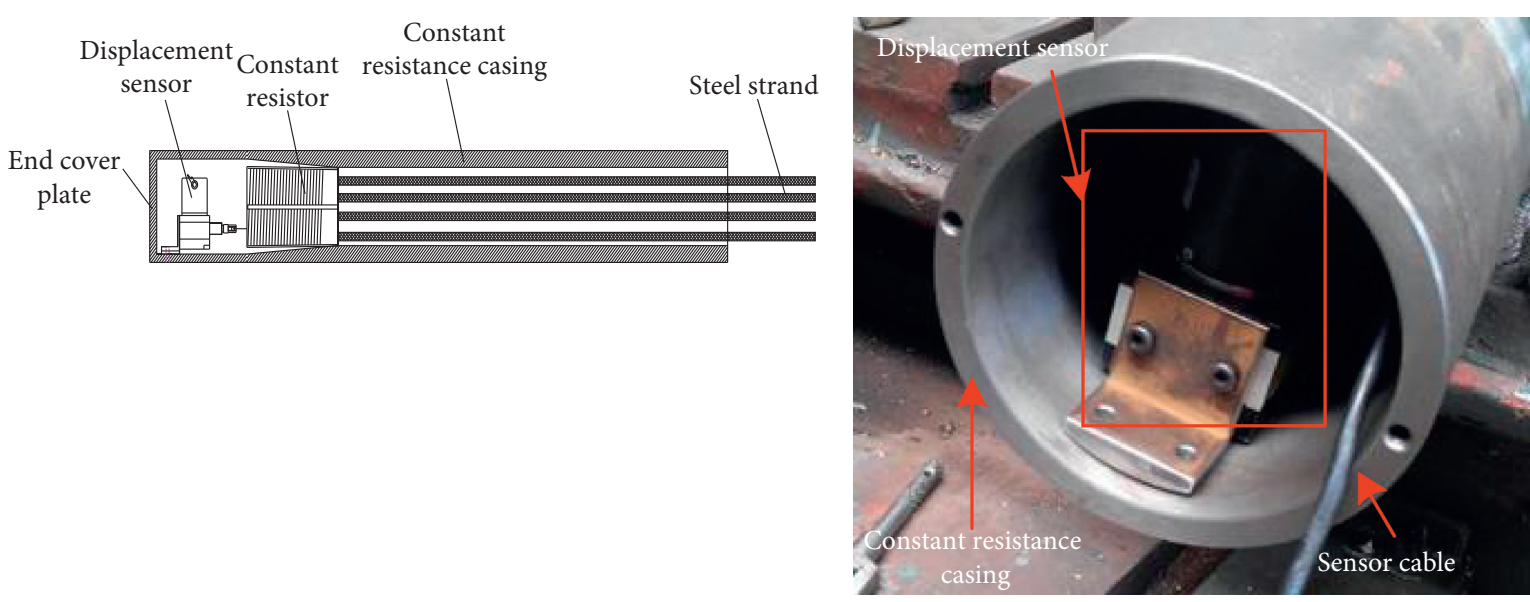

(a)

(b)

FIgURE 10: Measuring device for the sliding distance of the constant resistance body.

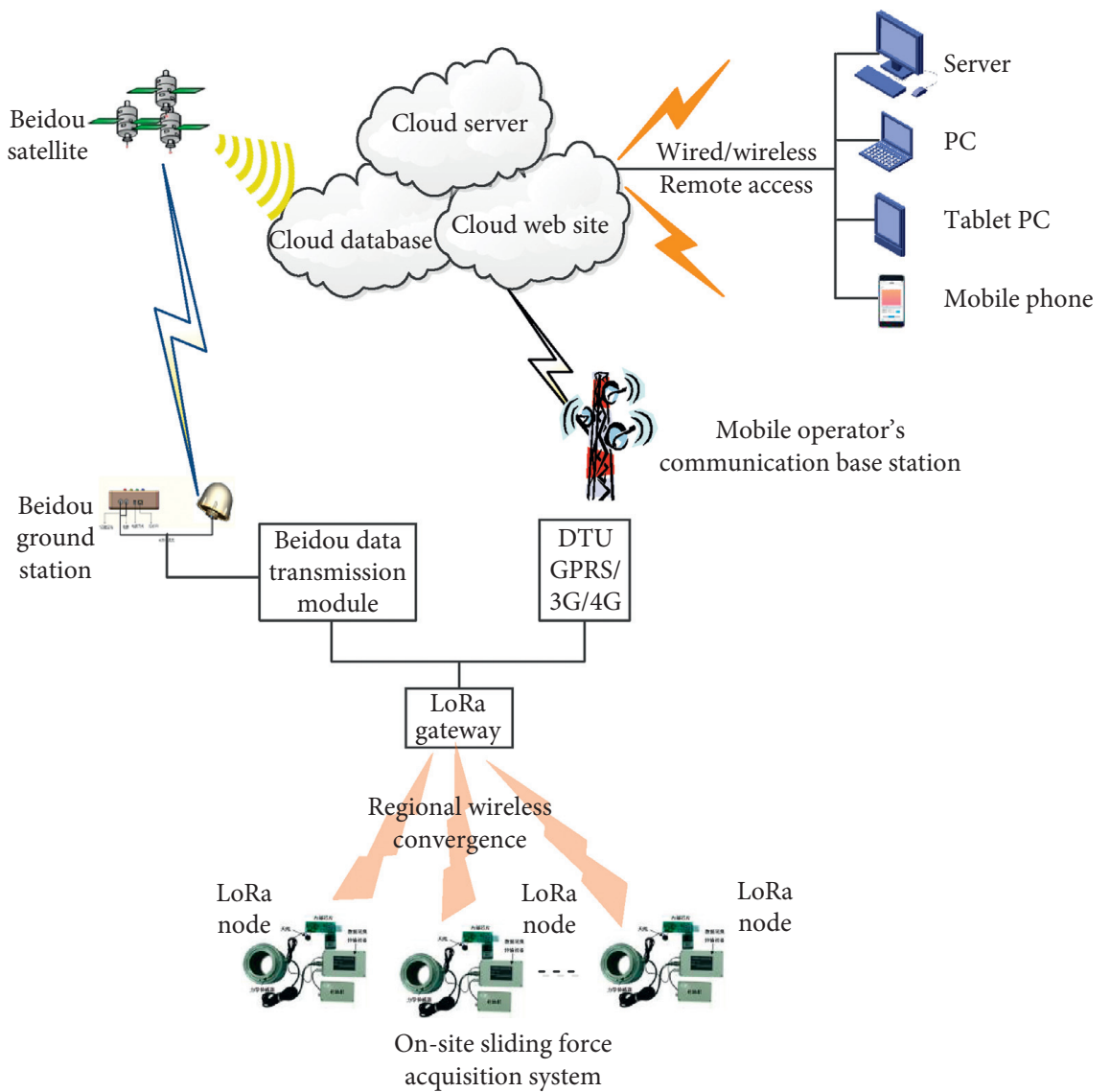

FIGURE 11: Network communication architecture diagram of the sliding force monitoring system.

for discriminant verification. As long as one set of data is correct, the transmission process is considered successful. Otherwise, a data request will be reinitiated until it is successful, which greatly improves the reliability of data reception.

This design eliminates the later operation cost of installing a mobile operator data flow card at each monitoring point, and the network coverage is much more extensive than other regional wireless transmission modes. Although redundant, this method of communication adopted in the middle and back end, with the help of the Beidou communication network, achieves seamless coverage of remote data transmission in remote areas. This greatly improves the reliability of data communication in remote mines. 


\subsection{Improvement of Upper Computer Software Architecture.} In the original slope sliding force monitoring and early warning system, a server with an independent IP is needed to receive monitoring data from the site. The database storage software and information publishing and displaying software are also installed on the server. The structure has the following problems:

(1) Data acquisition over a long time span involves a large amount of data. The speed of data invocation depends on the performance of the server. More massive datasets require longer invocation time, which directly affects the user experience.

(2) The storage capacity and expansion space of the system are limited. Upgrade, transfer, and backup of the system need to be handled manually by professionals. The flexibility of the system is low.

(3) Using one server to store and manage multiple project data is tedious, and there is a risk of data loss, causing the overall reliability of the system to be low.

The emergence of cloud computing technology allows the above problem to be solved. The high and steep slope monitoring and early warning system based on the cloud service platform software architecture has greatly improved its flexibility, stability, and scalability. The specific cloud service platform system architecture is shown in Figure 12.

The content of system architecture optimization of the cloud service platform is as follows:

(1) The data transmission reliability was greatly improved, the maintenance of the system decreased, and the reliability of cloud disk data reached $99.9 \%$. Once downtime occurs, the data automatically migrate with the help of an automatic snapshot backup function, and data recovery is fast and straightforward. In the past projects, mine owners needed to manage high-performance servers to maintain stable operation of the system. The insufficient technical strength of mine informatization results in unsatisfactory operation of the slope monitoring and early warning system. After using the cloud service platform system architecture, there is no need for mine hardware system maintenance, and the reliability of the system operation data and the sustainability of monitoring data are fully guaranteed.

(2) The cloud server ECS (Elastic Compute Service) is a flexible and scalable computing service, which can achieve the real-time dynamic scaling of virtual machines according to the performance of data statistics. That is, real-time monitoring of the status of virtual machines and dynamically adjusting the number of virtual machines as required according to the size of the resources needed for business data processing. This allows for flexible control of the system and a reduction in the time needed for calling large amounts of data. These aspects allow for a superior user experience.
(3) The cloud server integrates three core elements of traditional internet application: computing, storage, and network. It can quickly realize distributed deployment, which meets the unified and integrated operation of each mine slope monitoring and early warning system, and facilitates the dynamic joining of new slope monitoring projects, which makes the system highly flexible and expandable.

The publishing software interface of the monitoring system deployed on a cloud server is shown in Figure 13, which shows the geographical location of the landslide monitoring systems that have been built in China. Users can click on the yellow points on the map to obtain real-time monitoring data from that site.

The new software architecture and platform software solve the problems of slow query speed and poor running reliability of a physical server and do not need the hardware configuration upgraded and maintained regularly. The reliability of the system data is greatly improved, and the migration of the system has enough flexibility, which can help researchers focus on the analysis of data, rather than being preoccupied with the system maintenance.

\section{Engineering Application and Result Analysis}

3.1. Project Overview. The Nanfen Open-pit Iron Mine of Benxi Iron and Steel Group is one of the largest single openpit iron mines in Asia. Currently, the highest slope is nearly $700 \mathrm{~m}$, and the stage slope angle is at 46-54 degrees. According to technical specifications, this classifies the slope as a superhigh and steep slope. Most of the rock formations in the mining area are chlorite schist, amphibole chlorite, and quartz chlorite schist. The structure is powdery, flaky, or slate-like. After absorbing water, the strength sharply decreases. Due to weathering and erosion caused by surface water, it is easy to form a potential sliding surface in the slope.

In May 2014, nine new sliding force monitoring points were designed on the old sliding body on steps $478-526 \mathrm{~m}$ according to the scale and structure characteristics of the landslide body in the lower wall of the open pit and the requirement of the surrounding enlargement for the safety monitoring of the slope. The new sliding force monitoring points adopted the constant resistance cable with an optimized structure, increased constant resistance, and large deformation of the sliding measuring device of the constant resistance body. The monitoring points used the reverse installation method, and the initial prestressing force was $\sim 300 \mathrm{kN}$. At the beginning of installation, the GPRS point-to-point transmission mode was used to collect monitoring data remotely, and later it was changed to collect data via LoRa wireless. The LoRa gateway was installed at step $522 \mathrm{~m}$ to receive the sliding force monitoring data on the slope and uploaded to the remote cloud server through GPRS and the Beidou dual links. The distribution of monitoring points is shown in Figure 14. 


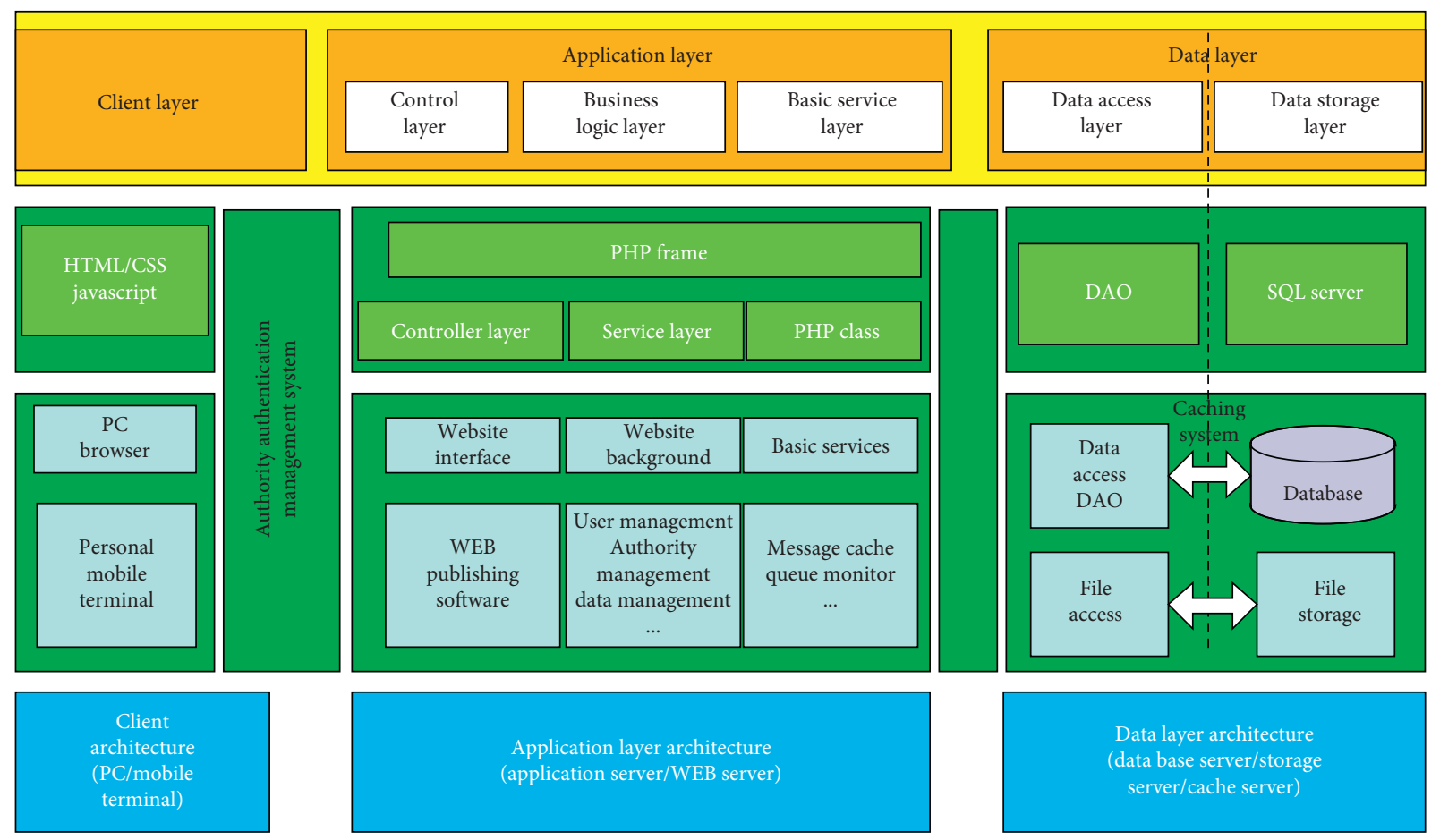

FIGURE 12: Architecture diagram of the cloud service platform system.

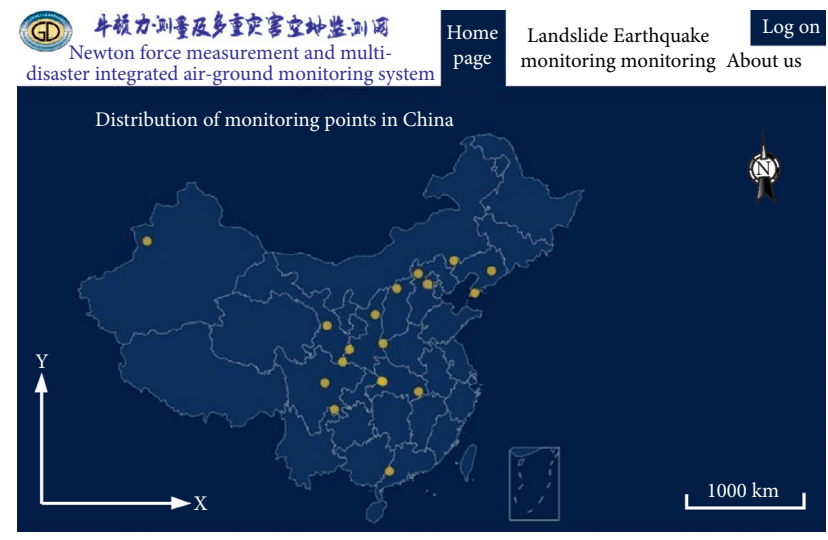

FIGURE 13: The publishing software interface of the monitoring system deployed on a cloud server (schematic diagram of monitoring points deployed in China).

3.2. Monitoring and Early Warning Process. The new sliding force monitoring points were enabled after the completion of construction at the end of 2014. The collection and distribution software deployed on the remote cloud servers dynamically records the monitoring data of each monitoring point in real time. The monitoring group timely releases early warning information at all levels according to the preset warning criteria. In the early morning of November 1 , 2016, a local landslide (collapse) occurred near the 23\# exploration line along the $502-430 \mathrm{~m}$ bench of the footwall of the slope. Due to the reasonable location of the monitoring points and the accurate and timely release of the early warning information, the landslide did not cause injury to personnel or equipment losses. Monitoring data showed that the construction of the high and steep slope sliding force monitoring and early warning system effectively played a role in ensuring safe production. The monitoring and early warning process is analyzed as follows.

From January 10, 2015, until the landslide occurred, there were four significant sudden changes in NO.478-3 sliding force monitoring point of the footwall of the Nanfen Open-pit Iron Mine (points A, B, C, and D as shown in Figure 15(a)). Because points A, B, and C failed to reach the warning level corresponding to the warning criteria, the system did not send a warning, and the disturbance factors and related conditions of the corresponding slope area were discussed at the production team meeting where workers were reminded to take note of slope conditions [22].

By point D (September 7, 2016), the sliding force increased by more than $300 \mathrm{kN}$, and there was a sudden increase again, but no significant change in the displacement sensor data at this time. According to the early warning criteria, the monitoring team issued a long-term early warning for the region on September 7, 2016, and the manager of the mine asked to increase the monitoring frequency of this point.

By October 1, 2016, the increasing trend in the sliding force at the monitoring point ceased, and the monitoring curve showed a gentle trend. The data of the displacement sensor remained unchanged. By October 1, the cumulative increment of the sliding force at the monitoring point exceeded $500 \mathrm{kN}$. The monitoring group timely issued a midterm warning and took corresponding hedging measures. Specialized personnel observed the monitoring data and the stability of the site slope, recorded and reported 


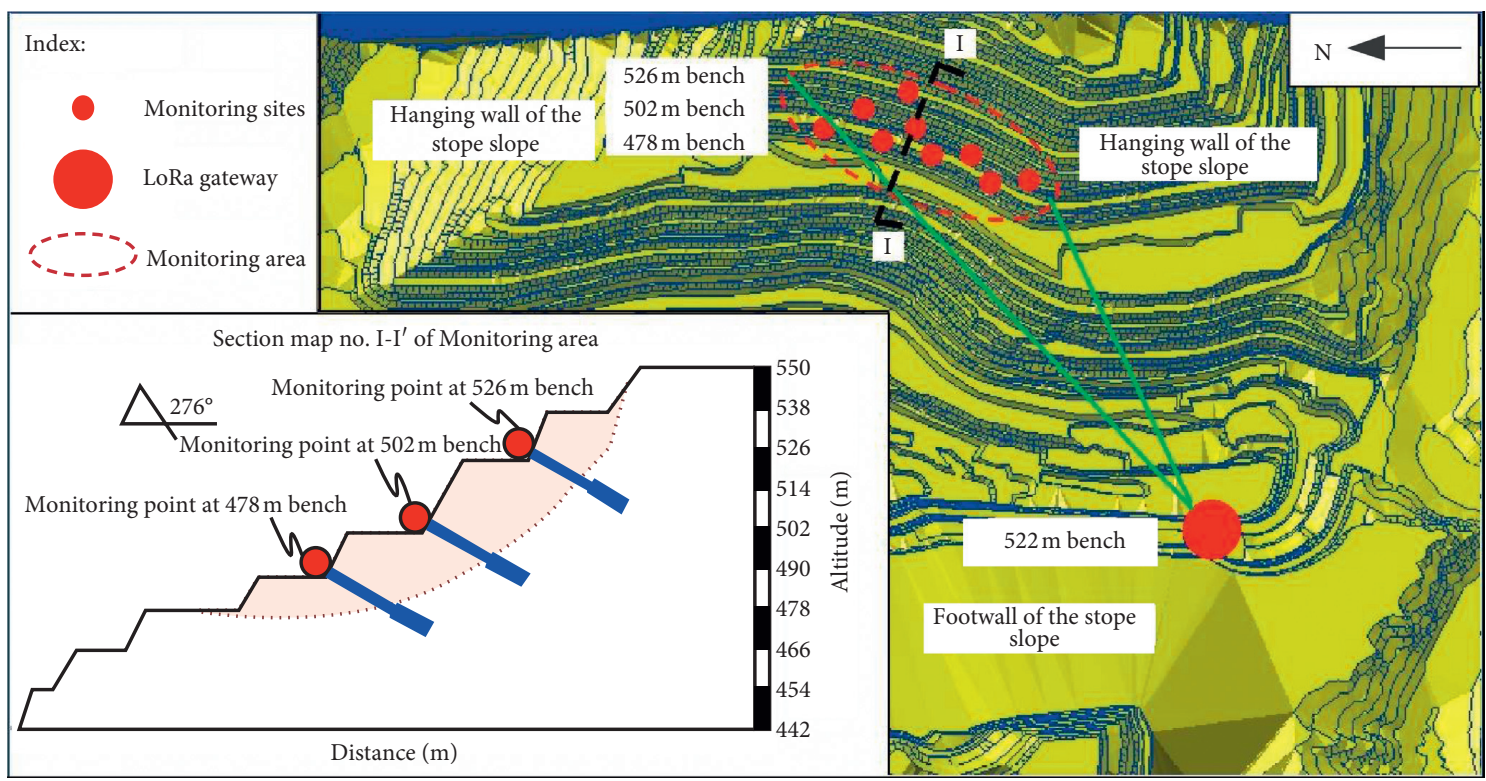

FIGURE 14: Distribution of the sliding force monitoring points.

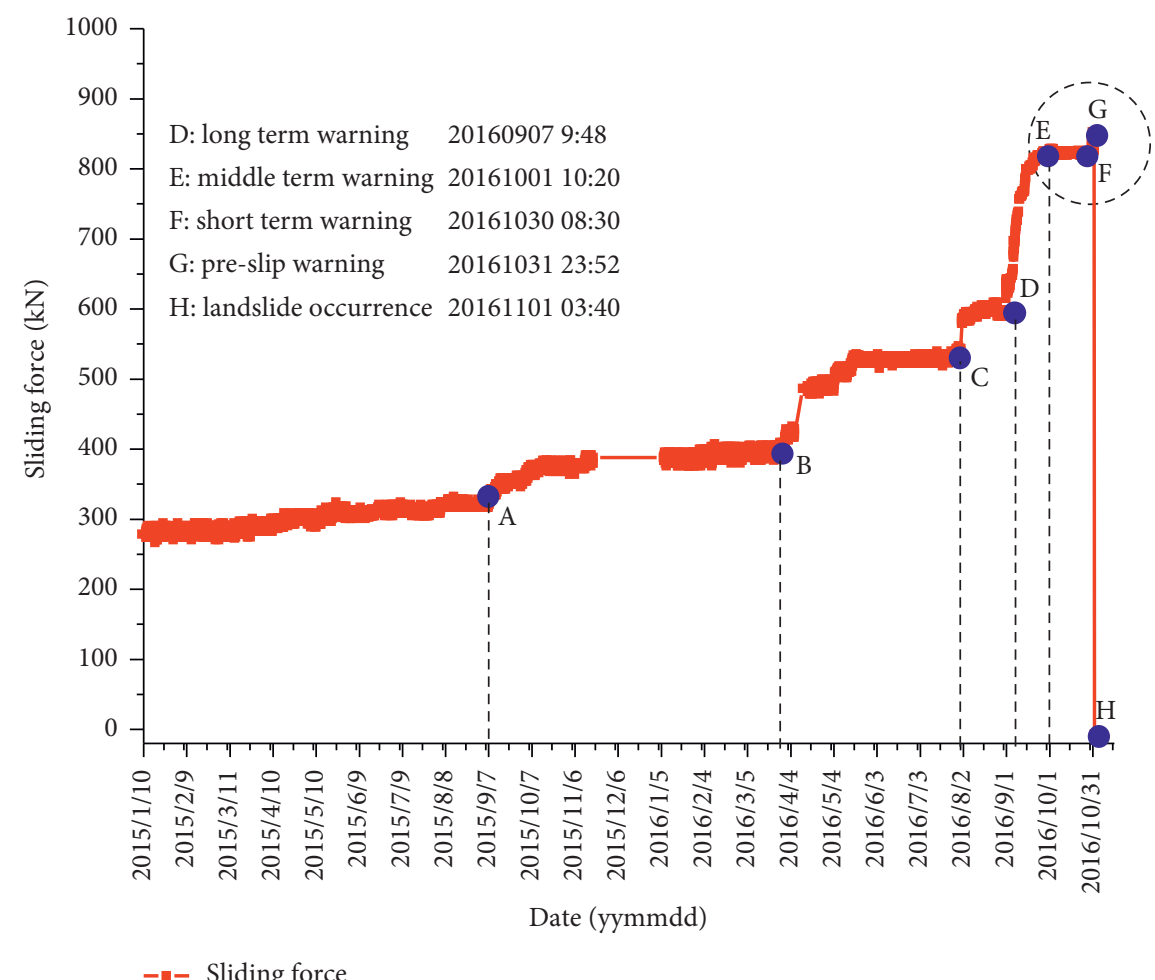

(a)

Figure 15: Continued. 


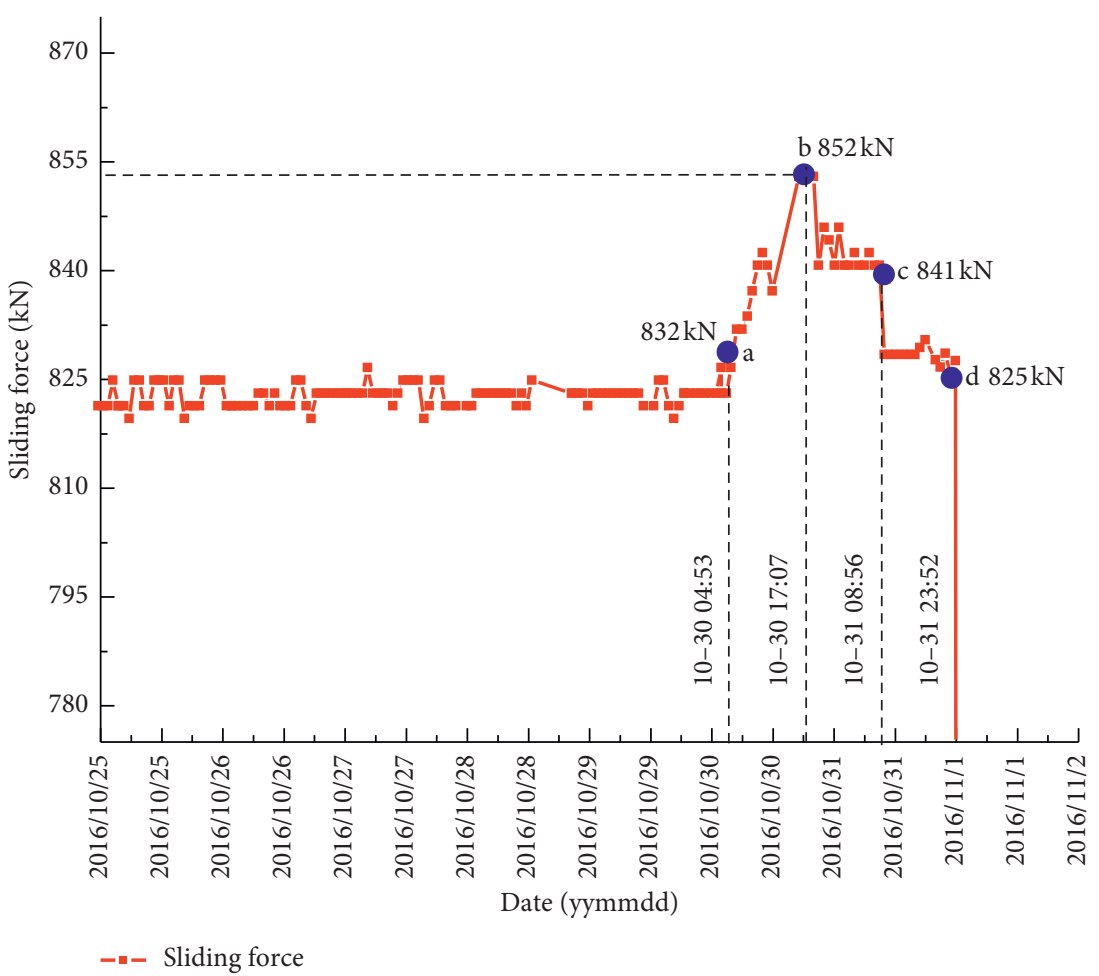

(b)

Figure 15: Monitoring curve of the sliding force (point no. 478-3).

every hour, and decided whether to continue production according to the development of the monitoring data.

On October 30, 2016, the monitoring data of the mining area showed a sudden increase once again. The cumulative increment of the sliding force reached $550 \mathrm{kN}$ and continuously increased. There was no noticeable change in the displacement sensor data. At 8:30, the monitoring group issued a short-term warning. The decision-making level of the mine decided to withdraw largescale equipment and operators. Only one observer remained at the site to remotely observe slope dynamics.

At 17:00 on October 30, 2016, the sliding force began to decrease after reaching $852 \mathrm{kN}$ (Figure 15(b)), indicating that the sliding force of the landslide body had reached the maximum constant resistance value of the anchor cable at this time. The cumulative decline was more than $20 \mathrm{kN}$ at night on October 31. At the same time, the monitoring data of the displacement sensor showed that the constant resistance body slipped slightly, and crack displacement occurred inside the slope. At 23:52 (point 15B-D), the monitoring data showed that the sliding force dramatically dropped. The displacement sensor monitored the rapid rise of the displacement value of the constant resistance body. The monitoring group issued a warning of near-sliding, and all personnel and equipment were withdrawn. At 3:40 a.m. on November 1, a landslide occurred in the slope of the lower wall of the slope, causing a tremendous noise. Large amounts of rubble rolled along the slope and accumulated on step $430 \mathrm{~m}$, which resulted in a height difference of about $3.5 \mathrm{~m}$ along the slope at the back edge of the landslide (Figure 16) [22].
The site investigation after the landslide shows that

(1) Landslide 2016-1101 at the footwall of the Nanfen Open-pit Iron Mine is classified as translational slides or wedge slide. Internally, two groups of largeangle staggered structural planes developed in the sliding body and produced staggered cutting damage to the rock mass and induced wedge failure. Externally, the precipitation on October 30 (rain to snow) induced the landslide. Green mudstone and chlorite amphibolite schist are dominant in the 526-430 $\mathrm{m}$ bench and 430-358 $\mathrm{m}$ bench of the lower wall slope of the open-pit mine. The potential sliding surface formed when the strength of the chlorite stratum was significantly reduced due to the precipitation.

(2) The monitoring data show that the threshold sliding force of this landslide was about $852 \mathrm{kN}$. The previous several sudden increases in the sliding force indicate the incubation process of the landslide. The sliding force only started to decrease after reaching $852 \mathrm{kN}$. This decrease indicated that the landslide would occur soon after.

(3) The sudden occurrence of the landslide was intense, which is reflected in the fact that the landslide body had not completely disintegrated, but layered subsidence occurred. That is, each step sunk to the next step as a whole (e.g., step $478 \mathrm{~m}$ sunk to step $466 \mathrm{~m}$ as a whole, and the rock mass remained intact, and cracks were not developed, as shown in Figure 17). 


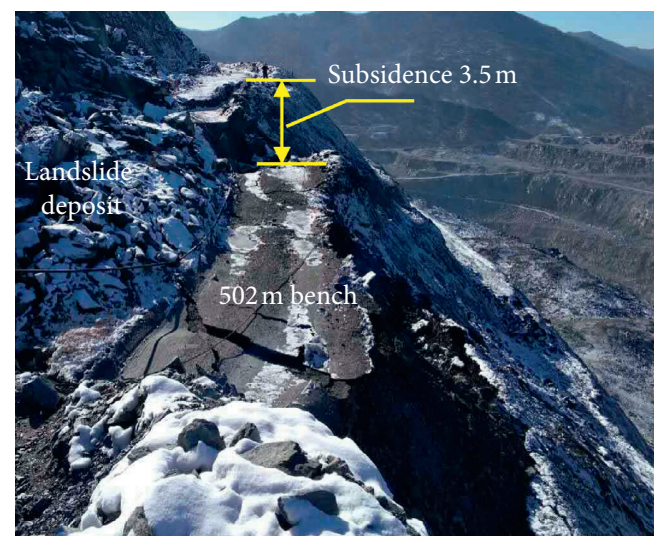

FIGURE 16: The overall subsidence of 502 level part steps.

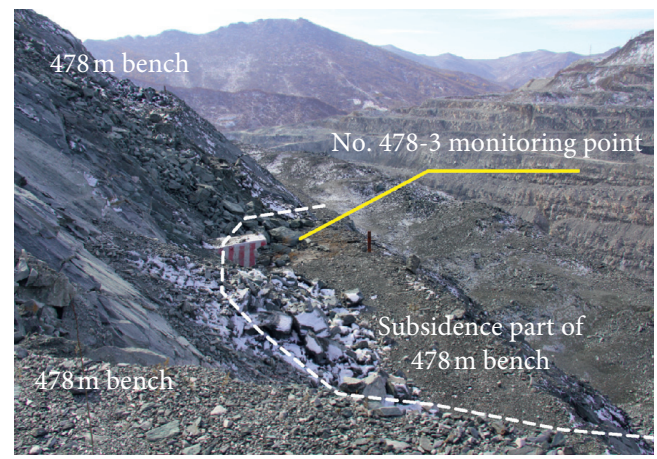

Figure 17: Part of the platform of step $478 \mathrm{~m}$ slid down to step $466 \mathrm{~m}$.

The tongue of the landslide sunk to step $430 \mathrm{~m}$ and the monitoring pier of NO.478-3 monitoring point was deposited. Following the overall slide of the sinking platform, the monitoring pier was not damaged, but the constant resistance body was pulled out entirely and buried in the gravel.

\section{Conclusion}

This paper reports the experimental results of several improvements performed on the original sliding force monitoring system with a focus on problem solving of the system, such as constant resistance fluctuation and easy pipe jamming. Monitoring of slope sliding force is affected by many factors, such as the scale, structure, and depth of sliding surface, and it is necessary to analyze different conditions and improve the monitoring instrument case by case. Thus, early warning criteria should be defined carefully based upon site-specific conditions. The following conclusions from the study can be drawn:

(1) By adding chip grooves and threads on the constant resistance body, the constant resistance characteristics of the large deformation anchor cable are effectively improved and system failure caused by constant resistance body clamping and constant resistance fluctuation can be avoided.
(2) Improvement in the installation method of the constant resistance and large deformation cable and the measurement of the displacement inside slope significantly improve the adaptability, effectiveness, and reliability of the monitoring and early warning system based on the sliding force in complex slope environments.

(3) Improvement of the communication mode finds a balance between flexibility and operating costs. The introduction of a cloud server improves the computing power of the system when processing a large number of monitoring points, which dramatically improves the user experience compared with the original physical server.

(4) The collected data show that the improved sliding force monitoring system can accurately reflect the whole process of landslide incubation. Moreover, the validity of the early warning criterion based on the sliding force is verified once again. The improvements applied in this research were systematically described to provide an example of good practice for other sites with similar features.

\section{Data Availability}

The data used to support these findings are included within the article.

\section{Conflicts of Interest}

The authors declare that there are no conflicts of interest regarding the publication of this paper.

\section{Acknowledgments}

This research was supported by the National Key Research and Development Program of China (Grant no. 2017YFC0804604) and the National Natural Science Foundation for Young Scientists of China (Grant no. 41502323).

\section{References}

[1] Z. Qin, H. Fu, and X. Chen, "A study on altered granite mesodamage mechanisms due to water invasion-water loss cycles," Environmental Earth Sciences, vol. 78, no. 14, p. 428, 2019.

[2] J. Wang, S.-C. Li, L.-P. Li, P. Lin, Z.-H. Xu, and C.-L. Gao, "Attribute recognition model for risk assessment of water inrush," Bulletin of Engineering Geology and the Environment, vol. 78, no. 2, pp. 1057-1071, 2019.

[3] Z. Chun, T. Zhigang, Y. Sen, and Z. Shuai, "V shaped gully method for controlling rockfall of high-steep slope in China," Bulletin of Engineering Geology and the Environment, vol. 78, no. 4, pp. 2731-2747, 2019.

[4] N. Wu, Z. Z. Liang, J. R. Zhou, and Y. Z. Zhang, "Energy evolution characteristics of coal specimens with preformed holes under uniaxial compression," Geomechanics and Engineering, vol. 20, no. 1, pp. 55-66, 2020.

[5] A. Li, Y. Liu, F. Dai, K. Liu, and M. D. Wei, "Continuum analysis of the structurally controlled displacements for largescale underground caverns in bedded rock masses," 
Tunnelling and Underground Space Technology, vol. 97, Article ID 103288, 2020.

[6] N. Jiang, C.X. Wang, H.Y. Pan et al., "Modeling study on the influence of the strip filling mining sequence on mining-induced failure," Energy Science \& Engineering, pp. 1-17, 2020.

[7] M. Pirone, R. Papa, M. V. Nicotera, and G. Urciuoli, "In situ monitoring of the groundwater field in an unsaturated pyroclastic slope for slope stability evaluation," Landslides, vol. 12, no. 2, pp. 259-276, 2015.

[8] M. Salvoni and P. M. Dight, "Rock damage assessment in a large unstable slope from microseismic monitoring-MMG Century mine (Queensland, Australia) case study," Engineering Geology, vol. 210, pp. 45-56, 2016.

[9] Y. Ohnishi, S. Nishiyama, T. Yano, H. Matsuyama, and K. Amano, "A study of the application of digital photogrammetry to slope monitoring systems," International Journal of Rock Mechanics and Mining Sciences, vol. 43, no. 5, pp. 756-766, 2006.

[10] K. S. Osasan and T. R. Stacey, "Automatic prediction of time to failure of open pit mine slopes based on radar monitoring and inverse velocity method," International Journal of Mining Science and Technology, vol. 24, no. 2, pp. 275-280, 2014.

[11] M. Xu, Y. Gao, H. Zhang et al., "Application of three-dimensional laser scanning technology in open pit slope monitoring," Journal of University of Science and Technology Liaoning, vol. 38, no. 3, pp. 217-220, 2015.

[12] L. Jun, W. He, W. Qiuling, and L. Xiaoyang, "Application of UAV remote sensing technology in open-pit slop mapping," Infrared and Laser Engineering, vol. 45, no. 1, pp. 111-114, 2016.

[13] Y. Guobin, T. Zhigang, S. Guanglin, and J. Kun, "Application analysis of slope stability radar in the mine slope monitoring risk area," Industrial Safety and Environmental Protection, vol. 41, no. 10, pp. 57-60, 2015.

[14] Y. Chen, R. Chen, and Z. Liang, "Testing study on applications of time domain reflectometry to slope monitoring," Chinese Journal of Rock Mechanics and Engineering, vol. 23, no. 16, pp. 2748-2755, 2004.

[15] W. Tao, L. Gan, L. Bo, L. Xiaojun, and W. Lei, "Application of sliding inclinometer in open-pit mine slope monitoring," Opencast Mining Technology, vol. 32, no. 1, pp. 12-15, 2017.

[16] Q. Dandan, L. Xinhai, and L. Pei, "Monitoring and earlywarning system of the high and steep slope in daye mine based on GPS and GIS," Journal of Wuhan Institute of Technology, vol. 32, no. 1, pp. 16-18, 2010.

[17] C. Lei, Z. Xuesheng, T. Yixian, and Z. Hong, "Deformation monitoring of the daguangbao landslide with time series InSAR technique," Journal of Mining Science and Technology, vol. 1, no. 2, pp. 113-121, 2016.

[18] M. He, T. Xue, and Y. Peng, "A new way of determining mechanical parameters of engineering rock masses," Chinese Journal of Rock Mechanics and Engineering, vol. 20, no. 2, pp. 225-229, 2001.

[19] M. He, "Real-time remote monitoring and forecasting system for geological disasters of landslides and its engineering application," Chinese Journal of Rock Mechanics and Engineering, vol. 28, no. 6, pp. 1081-1090, 2009.

[20] M. He, "Research on the double-block mechanics based on Newton force measurement," Chinese Journal of Rock Mechanics and Engineering, vol. 35, no. 11, pp. 2161-2173, 2016.

[21] Z. Tao, H. Li, S. Guanglin et al., "Development of monitoring and early warning system for landslides based on constant resistance and large deformation anchor cable and its application," Rock and Soil Mechanics, vol. 36, no. 10, pp. 3033-3040, 2015.

[22] Z. Tao, Y. Wang, C. Zhu, H. Xu, G. Li, and M. He, "Mechanical evolution of constant resistance and large deformation anchor cables and their application in landslide monitoring," Bulletin of Engineering Geology and the Environment, vol. 78, no. 7, pp. 4787-4803, 2019. 